\title{
Impact of Implementing ISO 9001 in the IT Sector in Business of Companies, and Customer Satisfaction
}

\author{
Mirhat Đulić
}

\begin{abstract}
Organizations that operate in the market and are trying to work successfully and thrive, they must act globally. Last decade of the last century, testified that he began a period of global competition, which is marked with standard breakthrough of the world market orientation and international organizations. The free flow of products is increasing and customers are getting more and more choices and thus becoming more demanding wanting always new and better products. Today's customers are compared to a few decades away more informed, the standards are higher and they become larger requirements. They began to realize that to have a lot of options available and one of them depends on where and what will they buy and what services are willing to pay. Developed countries have recognized the importance of the changes that are happening and started to work on creating the conditions that their organizations are better than the competition in order to survive in the market, and thereby create favorable conditions for the advancement of the country. Will there be a quality problem or a resource of an organization depends primarily of a basic attitude toward quality that exists in the organization. Implementation of the quality management system and obtaining ISO 9000 certification is not an easy task. The purpose of ISO 9000 is to ensure that any product produced most effective and efficient manner. Computer software that is ubiquitous in the activities they are engaged in the organization must be set as an object fitting into the overall system of quality according to standard ISO 9000.
\end{abstract}

Index Terms-Customer satisfaction, implementation, ISO 9001, IT.

\section{INTRODUCTION}

International Standard ISO 9001 promotes the adoption process approach when developing, implementing and improving the effectiveness of the quality management system, to enhance customer satisfaction by completing its requirements. For the effective functioning of the organization must identify and manage numerous interrelated activities. Activity or set of activities that use resources and managed in order to enable the transformation of inputs into output can be thought of. Often the output from one process directly enters the following process.

The application of the process in an organization, together with the identification and interactions of these processes, and governance in order to achieve the desired results, it can be regarded as a 'process approach'. The advantage of the process approach is ensuring permanent supervision of the links between the individual processes within the system of processes, as well as over their combination and interaction.

Manuscript received March 5, 2013; revised May 11, 2013.

M. Đulić is with the Faculty of Information Technology, Mostar, Bosnia and Herzegovina (e-mail: mirhatdjulic@gmail.com).
Quality management system model based on the process approach is shown in Fig. 1 shows the process connections presented in chapters 4 through 8 standards ISO 9001. This illustration shows that customers play a significant role in defining requirements as inputs. Monitoring of customer satisfaction requires the assessment of information concerning the buyer's perception of whether the organization has met customer requirements.

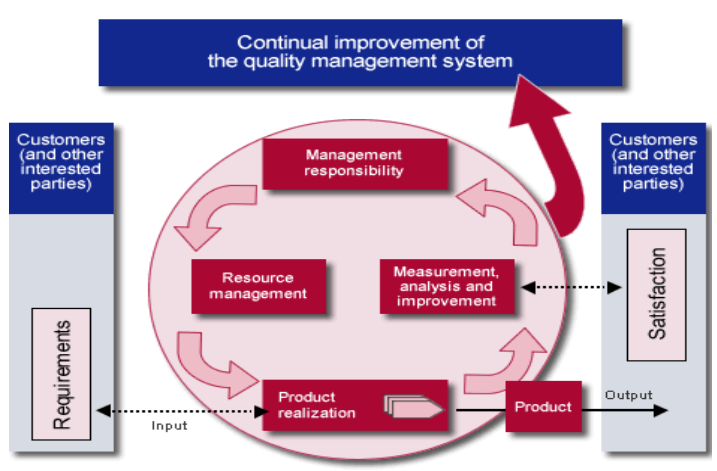

Fig. 1. ISO 9001 model.

\section{OVERVIEW OF RELATED RESEARCHES}

The general idea of the quality standards and assessed its specific usefulness in the information sector. Presented is a series of ISO 9000, with an emphasis on identifying the different types and purposes of standards and criteria discussed IT sector for the selection of appropriate standards. Presented and discussed a systematic review of the main critical points. Based on this analysis, identified some critical success factors for the implementation of ISO 9000. It is shown how an organization can avoid the pitfalls and dysfunction ISO 9000 consciously choosing and using a set of parameters to be implemented quality system fit the specific situation and the needs of individual organizations. Further, the new model for the implementation of an independent (situational or contingency factors) and the dependent variables (design parameters of the system quality). The model may be useful as a tool to facilitate the tailoring of ISO standards with special needs, the information sector of the organization. The analysis is based on theoretical considerations and preliminary results, NORDIC, project quality IT sector, whose purpose is to gain experience in the translation and interpretation of the ISO 9001 [1].

Establishing Quality Management System - QMS of any business system is one of the key elements of a successful business of any organization. Likewise, the establishment of quality IT sector is a prerequisite for the successful operation of the same, regardless of whether it is for the organization's main business process - a process that makes money in the 
market, or is it a process of support that is used to enable the main functions of the business process. Methods of establishing, maintaining and improving the quality of business systems is taking place in accordance with international standard ISO 9001:2000 which are as such by most countries in the world and declared as its national standard. ISO 9001:2000 is no different from the scope and types of organization and type of activities in them.

ISO 9001:2008 sets the criteria for quality management systems and is the only standard by which the family can be certified. It can be used by any organization, large or small, regardless of its field of action. ISO 9001:2008 has been implemented in over a million companies and organizations in more than 170 countries.

In the period of the past 15-odd years on the world stage came from the family of standards ISO 9000 which had the basic task is to enable the buyer of goods and / or services to verify documented way to achieve the declared quality, and manufacturers to ensure continuity of production of products of the same quality or better with regular access in cases of negligence and breach of the Declaration. Introducing a new revision of ISO 9000:2000 special emphasis has been placed on the information system. It has gone so far as to be virtually no longer be a company or a part of it certified, if no certified and information system that is involved in their activities. In previous versions of the ISO 9000 standard that was not the case. It is possible to bypass and does not certify the information system [2].

The results of two surveys among European software houses in which one of the goals of this study was to determine the improvement of software processes that firms have achieved during the implementation of ISO 9000 are as follows:

The first survey was conducted among 20 German software vendors that received the ISO 9001 certificate. The study focuses on five elements of ISO 9000 quality system: code reviews and inspections, software testing, product and process measurements, measurement of quality costs, and demonstration of quality improvements. Many software houses included in the first study did not implement changes to these five elements. Thus, it appears that the introduction of ISO 9000 has not led to significant improvements. However, most companies are still deciding in favor of the introduction of ISO 9000 quality systems.

Another study was conducted to gain a better understanding of the improvements that can be achieved with the help of ISO 9000. Analyzed reports on the experiences of several hours, and interviews with quality managers from a total of 36 European software houses. The paper presents the ten key success factors that the respondents of our studies considered to be of great importance in the implementation of ISO 9000 quality systems [3].

How difficult is to develop the ISO 9001 certification process? As an ISO 9001 focuses on what to do and not to do it, and it is flexible and as such it should be easy to implement, at least for small companies. Some companies, however, argue that the high costs of implementation and require a large amount of documents represent a major obstacle to the implementation of ISO 9001. We believe that ISO 9001 is only common sense to make it as such should be easy to

http://www.iso.org/iso/home/standards/certification/iso-survey.htm implement. Project "Spike" has given us the opportunity to show that we were right. Our firm is keen to implement ISO 9001, not because they thought it was necessary, but because the market seems increasingly demanded [4].

The government and many business organizations rely on the use of information to carry out their business activities. The loss of confidentiality, integrity, availability, accountability, authenticity and reliability of information and services can have a negative impact on the organization. Consequently, there is a critical need to protect data and manage the security of information systems within the organization.

With the significant advantages, the new technology introduces new challenges for the protection of this information. Request for the protection of information is especially important in today's environment, because many organizations are internally and externally connected network of IT systems [6].

\section{DATA COLLECTION AND ANALYSIS}

From December 2012 to February 2013, we conducted a survey among the companies in Bosnia and Herzegovina that have received an ISO 9001 certificate. On the web page of Institute for standardization of Bosnia and Herzegovina we found that there are 995 ISO 9001 certified companies. We identified quality managers of 80 companies on the telephone and asked whether they were willing to participate in the survey. Companies were randomly chosen. All of them agreed and received a questionnaire that consisted of 10 questions. Twenty-one questionnaires were returned. We analyzed the answers, prepared a report. Some results are presented.

Fig. 3 shows that $42.86 \%$ of the organizations that implemented ISO 9001 in the IT sector reported improvement of efficiency, $4.76 \%$ reported much higher efficiency while the efficiency of $9.52 \%$ remained the same.

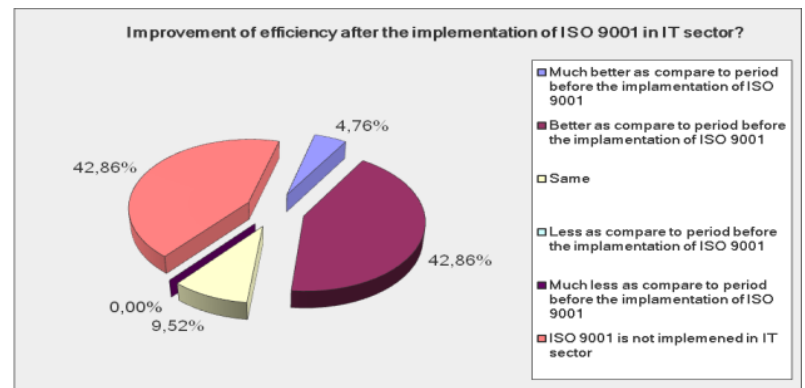

Fig. 2. Improvement of efficiency after the implementation of ISO 9001 in IT sector.

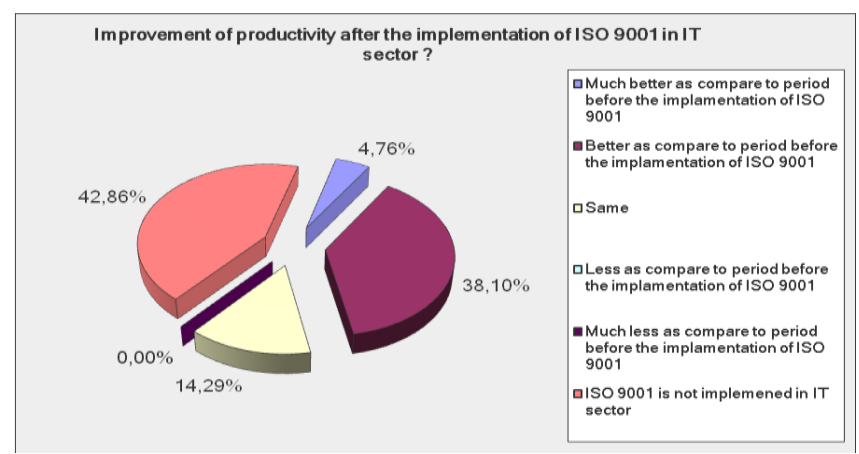

Fig. 3. Improvement of productivity after the implementation of ISO 9001 in IT sector 
Improvement of information security after the implementation of ISO 9001 ?

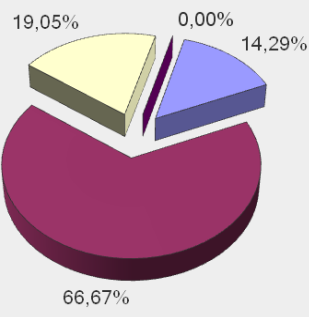

Much better as compare to period before the implamentation of ISO Better as compare to period befor the implamentation of ISO 9001 口Same Less as compare to period before Much less as compare to period 9001

Fig. 4. Improvement of information security after the implementation of ISO 9001.

Customer/service users satisfaction after the implementation of ISO 9001?

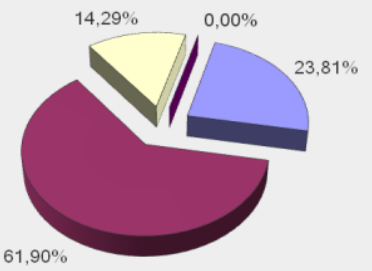
a Much better as compare to period before - Better as compare to period before asame the 9001 Muchless as compare to period
before the implamentation of ISO
Fig. 5. Customer/service users satisfaction after the implementation of ISO 9001.

Fig. 2 shows that $42.86 \%$ of the organizations that implemented ISO 9001 in the IT sector reported improvement of efficiency, $4.76 \%$ reported much higher efficiency while the efficiency of $9.52 \%$ remained the same.

Fig. 3 shows that $38.10 \%$ of the organizations that implemented ISO 9001 in the IT sector reported improvement of productivity, $4.76 \%$ reported much higher productivity while the productivity of $14.29 \%$ remained the same.

Fig. 4 shows that improvement of information security of the organizations that implemented ISO 9001 increased in $66.67 \%$ of organizations, $14.29 \%$ reported much higher improvement while the improvement of $19.05 \%$ remained the same.

Fig. 5 shows that customer/service users satisfaction of the organizations that implemented ISO 9001 increased in $61.90 \%$ of organizations, $23.81 \%$ reported much higher improvement while the improvement of $14.29 \%$ remained the same.

It is significant that in neither organization had been no deterioration by any of criteria.

The presented results show $75-80 \%$ of organizations that have implemented ISO 9001 in the IT sector reported some improvements in business. Although, our research shows improvements didn't produce very significant results, it can help set some usable bearings for future research.
Certification bodies and customers/service users should be surveyed and results compared.

\section{CONCLUSION}

Organizations that operate in the market and are trying to work successfully and thrive, they must act globally. The free flow of products is increasing and customers are getting more and more choices and thus becoming more demanding wanting always new and better products. It can be said that the market as a top criterion for success narrowed the space for unprofessionalism, incompetence and poor quality. These developments are the most satisfying for customers.

In determining customer expectations organizations must avoid the mistake made by a number of them, and that is to create your own list of expectations and demands of customers. This is called organization point of view, which in most cases does not provide relevant information because customers and organizations do not have the same view of the product / service. In contrast to this method, if the determination of customer expectations starts from themselves, research results become more precise. Implementation of ISO 9001 can make a difference in the achievement of customer demands and goals of the company.

\section{REFERENCES}

[1] C. G. Johannsen, "Application of the ISO 9000 standards of quality management in professional services: An information sector case," Total Quality Management, vol. 6, no. 3, pp. 231-242, 1995.

[2] Z. Adelsberger, Information systems and standard ISO 9001:2000, 5. Symposium on Quality, Trogir, 27-29.03.2003., Hotel Medena, HR.

[3] D. Stelzer, W. Mellis, and G. Herzwurm, "Software Process Improvement via IS0 9000? Results of two surveys among European software houses," in Proc. 29th Annual Hawaii International Conference on System Sciences, 1996.

[4] T. Stålhane, "Implementing an ISO 9001 certified process," Norwegian University of Science and Technology - NTNU, 2006.

[5] ISO Survey. [Online]. Available: http://www.iso.org/iso/home/standards/certification/iso-survey.htm

[6] H. Hamidović, "Fundamental concepts of IT security assurance," ISACA Journal, vol. 2, 2012.

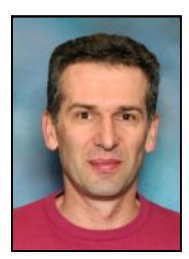

Mirhat Đulić was born at Zagorje, Lukavac, Bosnia and Herzegovina on January 13, 1968.

He received Economical Technician at Secondary economic school in Lukavac, Bosnia and Herzegovina in 1986.

He earned bachelor degree in engineer of mining at Faculty of Mining and Geology, University of Tuzla, Tuzla, Bosnia and Herzegovina, 2003.

Currently he is a student at postgraduate studies at Faculty of Information Technologies, University "Džemal Bijedić" Mostar, Bosnia and Herzegovina.

He served as MCT specialist in the North American Treaty Organizationled Stabilization Force in Bosnia and Herzegovina and LMCC Operation Coordinator in Iraq. 